\title{
Archivo diverso Costa Rica parte 2: Pinceladas de arte con diversidad
}

Recibido: 3 de febrero 2020

Revisado: 1 de abril 2020

Aprobado: 23 de mayo 2020

\section{Patricia Oliva Barboza}

Costarricense. Magister en Violencia de Género por la Universidad de Costa Rica, Costa Rica. Facilitadora en grupos de apoyo:

Apropiación del cuerpo por medio de la danza.

Practicante de danza moderna. Investigadora feminista, interesada en temas sobre corporalidades y arte, integrante del Centro de Investigación en Cultura

y Desarrollo de la Universidad Estatal a Distancia de Costa Rica,

Costa Rica. Correo electrónico: poliva@uned.ac.cr

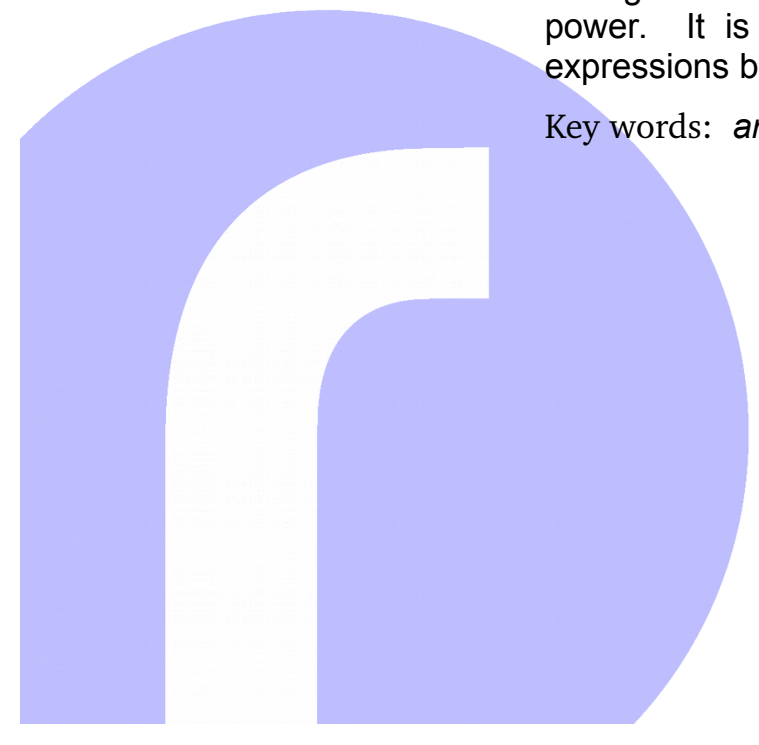

https://revistas.uned.ac.cr/index.php/rupturas (c) (1) (2)
Resumen: Si existiera un ejercicio constante, que registre las expresiones de arte diverso en el país, notaríamos su relevancia y el aumento de este tipo de creaciones artísticas. El objetivo de este artículo es presentar una nueva serie de relatos que suman en la construcción, ya no solo de un archivo, sino de un colectivo que crece, se afirma y fortalece, a pesar de su poca o nula visibilización. Mohanty, teórica feminista, reconoce que "la mejor teoría convierte en comunicable la experiencia personal y los relatos" (Mohanty en Bach 2010, p. 60). Estas 5 nuevas expresiones nos recuerdan la relevancia del arte como elemento expresivo por medio del cual visibilizar la disidencia y evidenciar su poder creativo. Aspiro que en un futuro cercano formen parte de una misma y única paleta de arte.

Palabras clave: archivo; arte diverso; transgresion; feminismo; diversidad

\section{Diverse Archive Costa Rica Part 2: Brush Strokes of Art with Diversity}

Abstract: If there existed a constant registration of the expressions of diverse art in the country, we would notice its relevance and there would be an increase in this kind of artistic creation. The objective of this article is to present a new series of accounts that add up to the construction, not just of an archive, but of a collection that grows, establishes itself and gets stronger, despite its little or non-existing display. Mohanty, theoretical feminist, recognizes that "the best theory transforms personal experience and accounts into something conveyable" (Mohanty in Bach 2010, p. 60). These 10 new expressions remind us of the relevance of art as an element of denunciation through which dissidence may be visualized, demonstrating its creative power. It is my aspiration that in the not-too-distant-future these artistic expressions become part of a same and unique palette.

Key words: archive; diverse art; feminism; transgression; diversity 
1. Ver:

https://www.upo.es/revistas/ind ex.php/atrio/issue/view/247

2. Proyecto de Artes Dramáticas inscrito en la Vicerrectoría de Acción Social de la UCR, coordinado por Grettel Méndez.

\section{Introducción}

Corro el riesgo de que mi investigación sea considerada "un simple registro de expresiones de arte", un archivo podría percibirse en el mundo académico como un simple listado, lo que me obliga a reiterar constantemente la relevancia de construir un archivo y "específicamente" un archivo diverso. Empiezo con el siguiente planteamiento: ¿existe un registro de los(as) artistas y las expresiones de arte que forman parte de este archivo diverso? ¿Quedarán documentadas estas expresiones de arte?, Cuando ni siquiera podemos garantizar que exista un archivo completo de arte, ¿de qué otra forma se podrían visibilizar estas expresiones disidentes?

En el artículo de mi autoría llamado Archivo Diverso Costa Rica. Primera parte. Expresiones de arte transgresor ${ }^{1}$, se incluye un texto detallado sobre la importancia de archivar, razón por la que no lo repetiré en este nuevo documento; pero sí quisiera subrayar que el ejercicio de archivar refiere a una cuestión de inexistencia; o sea, "no existen" iniciativas que registren este tipo de prácticas artísticas. Las expresiones de arte que acá se presentan son muy poco visibles, no se exponen de la misma forma que otras expresiones y no es fácil encontrarlas en espacios de arte.

Sobre este tema, en noviembre del 2019 fui invitada a presentar parte del archivo diverso en el encuentro Prácticas artísticas como rutas de mediación en la Universidad de Costa Rica (UCR) ${ }^{2}$. Como parte del encuentro, la artista plástica Natalia Astuáúacas diseñó un mural efímero con extractos de texto del archivo, acompañado de dos palabras: AQUÍ EXISTO. Esta instalación ejemplifica la función de un archivo para evidenciar prácticas artísticas que generalmente son invisibles. No existen espacios en los que ellos, ellas y elles aparecen como artistas. El arte no les reconoce, no les agrupa y no son considerados(as) como colectivo de arte, aclarando que son artistas con sus particularidades muy marcadas; sin embargo, colectivo al fin, con un interés común por incorporar la diversidad sexual en sus obras.

Para precisar el significado de archivo que se propone desde la investigación (de la cual se desprende este tercer artículo) me remito a Ana Marchante (2015), que señala: "Comúnmente utilizamos el término archivo para designar un conjunto ordenado de documentos y al espacio físico donde estos se conservan o para nombrar a la institución responsable de su custodia" (Marchante, 2015, 39). Dicho concepto tradicional de archivo me permite dilucidar que justamente la idea de archivo que se ha venido utilizando por artistas, colectivos diversos y feministas representa una ruptura tanto en la selección como en la forma en la que se construyen. La selección es políticamente intencional, como el caso de los archivos queer o de aquellos construidos por artistas feministas (que deciden coleccionar únicamente obras de mujeres artistas). Son archivos que se comparten en muy distintos espacios (no tradicionales) con la intención de visibilizar su trabajo. Es una selección de obras que no está presente dentro de la propuesta artística oficial; se trata, enton- 
ces, de desordenar las formas clásicas de archivar, sea por la selección en sí como por los formatos o espacios utilizados. En este mismo texto de Marchante, aparece la definición-contraste de archivo queer ofrecida por el artista Sejo Carrascosa: "el archivo surge para ocupar un lugar entre la memoria y el olvido, entre el orden y el caos. De esta manera, las preguntas sobre archivar y construir un archivo siempre van a implicar una cuestión de poder" (Carrascosa en Marchante 2015, p. 39).

Aclarado el significado de este archivo como herramienta disidente, identifico que uno de los primeros hallazgos en etapas tempranas de la investigación ha sido reconocer que la diversidad sexual (en nuestro país) ha permeado muchas prácticas artísticas, desde algunas más conocidas (como danza, teatro, plástica, cine y poesía) hasta también otras expresiones ( no tan conocidas, al menos en nuestro país, aunque antiguas en su creación) como el spoken word, el ballroom, el vouguing (baile que se practica dentro de la cultura ballroom) y el performance (sobre lo que volveré más adelante).

Los y las artistas se apropian y recrean estas prácticas a partir de novedosas propuestas políticas y estéticas, motivo por el cual llegar a definirlas no es tan simple; responde, por un lado, a un contexto histórico y geográfico y, por otro, a la re-construcción propia de cada artista o cada colectivo. Sin embargo, se comparten definiciones/fusiones entre referencias teóricas (pocas) en conjunto con definiciones construidas entre las y los artistas y quienes estamos generando este registro.

Sobre la práctica del ballroom en nuestro país, los y las artistas que han representado esta práctica (uno de los cuales forma parte del archivo) ofrecen una interesante reconstrucción que, como ya he mencionado, es una práctica que se realiza de manera distinta según el lugar, y el artista o la artista. En un intento por aportar una definición y después de consultar con otres artistes, resulta muy oportuna la definición de Marlon Bailey, que expone lo siguiente: "la cultura ballroom, que existe en la mayor parte de los centros urbanos de Norteamérica, es una comunidad y una red de personas negras y latinas LGBTQ" (Bailey, 2014). Ampliando esta cita, agrego que es una cultura que se expresa a partir de varias estructuras: las llamadas houses o "casas", que representan una forma de organizarse por afinidad y por vínculo, afectivo además del estilo artístico que se expresa gracias a los performances o rituales que se divulgan con la realización de eventos que integran y organizan las casas o houses.

El vouguing es uno de los bailes o expresiones que más se practica dentro de los colectivos que conforman la cultura ballroom. En Costa Rica, aún no existe consenso sobre su definición; empero, comparto algunos elementos (que desde otros países como México aportan en la construcción de un concepto). Tomado del sitio web de Cultura UNAM ${ }^{3}$, que divulga la primera exposición Elements of Vogue. Un caso de estudio de performance radical en 2019 entre México y España, que aunque se refiere a una exposición, aporta elementos que permiten comprender su significado:
3. CulturaUNAM es un proyecto de la Universidad Nacional Autónoma de México (UNAM), que germina a partir de una idea: a través del arte, se pueden realizar los cambios sociales indispensables para alcanzar un futuro esperanzador.

https://cultura.unam.mx/Cultu raUNAM 
4. Ver:

https://cultura.unam.mx/evento /elements-of-vogue-un-caso-deestudio-de-performance-radical -inauguracion

5. Definición de spoken word. https://es.m.wikipedia.org/wik i/Spoken_word
La exposición revisa la historia de la performance afroamericana, y la primera a nivel internacional sobre la historia del voguing, baile popular afrolatino y queer, como un caso de estudio para entender la emergencia de la pose como forma de resistencia y su capacidad para articular nuevas formaciones sociales. Elements of Vogue investiga cómo las minorías utilizan sus cuerpos para crear formas disidentes de belleza, subjetividad y deseo. El voguing es una forma de danza underground inspirada por las poses de las revistas de moda, inventada por cuerpos que han sido criminalizados, racializados, medicalizados y castigados una y otra vez. ${ }^{4}$

Se trata, pues, de un baile que re-significa el mundo de las poses y portadas de revistas. El mundo farandulero real es inalcanzable; no tiene cabida para muchas de las y los artistas, por lo que recrean su propio estilo fashionista y su propia fantasía. En las casas o houses y en los eventos, se reúnen para simular ese mundo; pero, al mismo tiempo, representa un lugar de encuentro y convivencia con personas que comparten una misma realidad de exclusión y discriminación por identidad sexual, situación económica y social.

Sobre el spoken word ${ }^{5}$, al primer intento de búsqueda aparece una clara y sencilla definición. Aun así, es necesario complementar dicha definición a partir de la reconstrucción propia de la artista (quien forma parte del archivo). No sin antes extraer el elemento histórico que resulta todavía más interesante que el mismo concepto. El spoken word es una práctica artística milenaria y ancestral heredada de nuestras raíces africanas como una tradición oral (poesía oral) para trasmitir creencias y costumbres entre generaciones. La artista Laura Contreras, que representa esta expresión, define el spoken word como: "poesía oral y corporal, poesía escénica y experimental donde puedo explorar otras artes e incorporarlas escénicamente tales como el canto, la performance, la música (en ocasiones utilizando instrumentos como la ocarina), además de la improvisación, todo ello en solitario o en compañía de otros(as) artistas" ( comunicación personal, 15 de ferebreo 2020).

En cuanto a la performance no existe una única definición; como he venido señalando con otras prácticas, son expresiones que dependen del contexto histórico-geográfico y la re-apropiación de los y las artistas. Empero, conviene conocer el significado histórico y el concepto que una mayoría de historiadores(as) de arte y artistas le confieren, que además es relevante para este artículo en particular, por el elemento político: 
Para muchos, performance refiere a una forma específica de arte, arte en vivo o arte acción que surgió en los años sesenta y setenta para romper con los lazos institucionales y económicos que excluían a artistas sin acceso a teatros, galerías y espacios oficiales o comerciales de arte. De manera repentina un performance podía surgir en cualquier sitio, en cualquier momento ${ }^{6}$ (Taylor y Fuentes 2011).

6. Ampliando la definición de performance: " el artista solo necesitaba su cuerpo, sus palabras y la imaginación para expresarse frente a un público que se veía a veces interpelado en el evento de manera involuntaria o inesperada. El performance, antiinstitucional, antielitista y anticonsumista viene a constituir una provocación y un acto político casi por definición, aunque lo político se entienda más como postura de ruptura y desafía que como posición ideológica o dogmática" (Taylor y Fuentes 2011). Justamente por los elementos que refieren a la intervención del cuerpo como herramienta política de lucha, el performance ha sido una de las prácticas artísticas más desarrolladas por el arte feminista.

https://investiga.uned.ac.cr/cicd

7. Ver:

https://www.upo.es/revistas/ind ex.php/atrio/issue/view/247 suman 10 en este archivo, que continúa en proceso de construcción y edición.

\section{El valor de la experiencia: un aporte del feminismo}

El sociólogo activista por los derechos LGBTI+ Miquel Missé advierte sobre la urgencia de recuperar las narraciones de personas que según la norma patriarcal son excluidas y encarnan la otredad; él lo hace desde su activismo intersexual, con un llamado atento a salir de la invisibilidad y la heteronormatividad. Para él siempre ha sido importante contar y preservar todo el recorrido, toda la historia para que las nuevas generaciones tengan un precedente: "Contar nuestra historia es otra importante trinchera, hasta ahora otrxs la han contado por nosotrxs" (Missé, 2018, 87). 
Como lo señalé anteriormente, la intención no es reiterar la importancia de archivar; aunque brevemente quisiera referirme al posicionamiento feminista que persiste en la relevancia de recuperar la historia no contada. Como ha señalado el sociólogo Missé, la historia debería quedar impresa de alguna forma para conocimiento de nuevas generaciones, que ojalá no se quede solo en un relato aislado (lo que también es poderoso); pero si además se suma y se convierte en un registro, va delineando una fortaleza de relatos.

La investigación feminista cuestiona la "supuesta" objetividad investigativa, por lo cual es relevante partir de un pronunciamiento claro: denunciar y hacer relectura de distintas formas de opresión patriarcal. La acción de registrar y crear un archivo "contra histórico" es considerado una selección totalmente política: "archivar es una especie de denuncia; en esta propuesta, el objetivo es denunciar esa ceguera heteronormativa, patologizante y excluyente que opera también en las artes" (Oliva 2019).

Resignificar la experiencia vivida es el primer paso en el proceso de recuperación y registro; sobre esto, el feminismo es pionero; la revalorización del conocimiento cotidiano, de acuerdo con la autora (Bach, 2010) es uno de los principales aportes de los estudios feministas, pues:

Cuestiona la innecesaria separación en tipos de conocimientos, supuestamente antagónicos, diferenciación que por añadidura, muchas veces conlleva la desvalorización del conocimiento ordinario, erigiendo a la ciencia en el único tipo de conocimiento a través del cual se alcanza la verdad (Bach 2010, 65).

Cuestionar las raíces de las "supuestas" verdades absolutas, que demás está decir, se hallan cargadas de androcentrismo y sus consecuentes sesgos, implica dotar de valor, "del mismo valor" para un conocimiento que surge desde otros espacios, que la autora llama simbólicamente "ordinarios". Este adjetivo lo podemos traducir como el conocimiento cotidiano, simple o subjetivo en resumen "no científico" y es precisamente el tipo de conocimiento que las teorías feministas han resignificado, en un primer momento para escuchar los relatos de las mujeres.

Ana María Bach inicia recordando la teoría de Haraway: la experiencia es sexuada; esto supone que las experiencias son distintas; por ejemplo, desde la condición de género los hechos se viven de manera distinta en hombres que en mujeres "porque sus lugares sociales son otros, además de ser diferentemente valorados" (Bach 2010, 19). Reitero que, así como desde las luchas feministas son las mujeres las voces que interesan, en un mundo hetero-normado y patriarcal, además de las mujeres, desde luego, serán los y las artistas que dialogan con la diversidad sexual, quienes mediante sus expresiones artísticas se convertirán en las voces principales de este archivo. 
Nadie más que la misma persona puede relatar su historia; nunca será igual una historia recuperada desde una revisión documental o bibliográfica previa, que tener la oportunidad de capturar de forma directa esa narración. Se trata de transferir los relatos encarnados que surgen a partir de las experiencias que desde el cuerpo se expresan y gracias al arte se traducen. La construcción del presente archivo se alimenta de los relatos directos, de los hechos más íntimos, aquellos que hicieron que los y las artistas se acercaran al arte; esos hechos significativos que vinculan su vida personal y sus expresiones de arte.

Sobre este tema, me resulta muy útil compartir un extracto de la entrevista realizada por Paz López a Jennifer McColl Crozier investigadora en artes escénicas, quien se ha interesado en documentar la vida de la artista, también chilena, Carmen Beuchat. La periodista le plantea una pregunta sobre el concepto de archivo dentro de las artes escénicas, a lo que la investigadora responde:

Carmen tiene su propio registro, su memoria, ¿cómo podemos nosotros incluir o rechazar sus relatos y recuerdos? Entonces, el archivo no podía pasar por sobre, sino al contrario, los sentidos de este archivo emergen a partir de esos recuerdos, que al disponerse públicamente toman una nueva urgencia, una nueva vitalidad a partir de aquello que no es posible archivar (López 2019).

\section{Construcción del archivo}

El criterio principal para la selección de los, las y les artistas en este archivo ha sido su obra o expresión final; es decir que la obra (producto de la práctica artística) dialogue explícitamente con la diversidad sexual, en sus muy variadas formas. Desde el primer archivo, se expone el significado de "diverso" y lo que ello va a representar durante todos los proyectos de investigación. Lo "diverso" alude a todas aquellas prácticas y expresiones artísticas que incluyan la temática de diversidad sexual en cualquiera de sus formas.

En principio, el rastreo de los primeros y las primeras artistas ha sido por el argumento explícito de su obra; antes, debo señalar que a partir de mi interés por estudiar las artes escénicas y por vinculaciones con anteriores investigaciones, así como por mi práctica en la danza, conozco la primera obra sobre temática trans de la artista Andrea del Valle, llamada La Quinceañera (Oliva 2019). Posteriormente, los y las mismas artistas han ido generando la ruta del archivo cuando sugieren a otros y otras colegas. En Archivo diverso Cos- 
ta Rica Primer Parte, se muestra un grupo de cinco artistas, (los detalles se pueden consultar en el enlace del artículo), pero me parece importante mencionarles para visibilizarles y así dar paso a un segundo grupo.

Abarcando las categorías de spoken word y performance, la feminista Mariana Alpízar, la actriz y dramaturga Andrea del Valle, el artista plástico y arquitecto Alejandro Rambar, la actriz Jimena Franco y el bailarín, coreógrafo y curador de danza, Christopher Unpezverde Núñez conforman la primera parte del archivo.

En esta segunda parte, participan: la dramaturga y poeta Angélica Azofeifa; la performancer feminista y poeta Laura Contreras; el bailarín y coreógrafo Adrián Figueroa; Minor Sánchez como representante de la cultura ballroom y la pintora y fotógrafa Susy Vargas.

Angélica Azofeifa. Actriz, dramaturga, poeta. Lugar y año de nacimiento: San José. 1983

Angélica es actriz y produce sus primeras obras siendo estudiante de la carrera de artes dramáticas. Le interesan otras expresiones como el performance y teatro comunitario, que ella misma señala que han sido producto de una necesidad personal por incidir en el espacio público: "necesito retomar para existir; esta necesidad de trabajar en espacio público y en comunidades tiene que ver con que, en ocasiones, las características propias del teatro no son suficientes" (comunicación personal 21 de junio 2018). Para ella, el teatro tiene una serie de procesos no inmediatos tan demandantes por los que prefiere otros procesos muy distintos, que requieren un trabajo serio pero fuera de la estructura teatral.

\section{Un proceso carnal distinto}

Esa otra "forma de hacer teatro" y el acercamiento con las comunidades, lo define como un "alejarse de la teoría de la composición profesional". Se refiere específicamente al trabajo con comunidades que al igual que ella, han sido víctimas de alguna forma de opresión y violencia; nos relata que el mundo escénico le ha permitido generar un espacio sagrado para mostrar las vulnerabilidades y realidades.

Inicia haciendo teatro desde sus épocas de colegio, por razones laborales lo abandona por aproximadamente diez años, aunque se mantuvo escribiendo y haciendo literatura. Realiza sus primeros cursos en el 2012 en el Teatro Giratablas; confiesa que inicia las clases de teatro como una opción de autocuido para alejarse del stress laboral. Ingresa a la carrera de artes dramáticas en la UCR y al mismo tiempo emprende una cafetería cerca del teatro, como una forma de mantenerse cerca. A partir de allí, se dedica con más constancia durante cuatro años a las artes dramáticas, momento en el que realmente 
se descubre como artista. Para Angélica el "ser artista" incluye mucha preparación, mentalidad y disposición: "hoy no tengo problema con que me digan artista porque creo que hay que consolidarse, lo que no quise hacer antes" (comunicación personal 21 de junio 2018).

Reflexiona sobre el control escénico y sobre el significado de la audiencia, cuestionándose sobre el espacio que se habita cuando se piensa en el escenario; nos confiesa que tenía la sensación de no contar con lo necesario para componer una obra teatral, y "entra al escenario" desde un lugar de absoluto respeto, por lo que se plantea algunas preguntas: “¿Qué puedo yo pedirle a una actriz a un autor, que puedo plasmar yo en una obra teatral para que un director de teatro me colabore? ¿Cómo voy a ponerme a diseñar un mundo literario si no sé cómo existe, cómo vive?" (comunicación personal, 21 de junio 2018). Así inicia su preparación en las artes escénicas, con una gran responsabilidad, conociendo el espacio-tiempo, con todos los elementos teatrales, teniendo claro su deseo de abarcar otras formas teatrales: "llegué a las artes dramáticas con un compromiso mucho más serio, pero a la vez con la urgencia de no quedarme ahí" (comunicación personal 21 de junio 2018).

Para Angélica la búsqueda en la dirección teatral ha sido algo constante, siempre se ha cuestionado la coyuntura nacional y cuál debe ser su lugar como artista, hoy confirma su posición desde una mirada de centro americana: "sin tirar mi mirada al norte, tirándola al sur, reconciliando, buscando temas" (comunicación personal 21 de junio 2018). Se cuestiona entonces temáticas como la migración, las problemáticas regionales tratando siempre de hacer incidencia que finalmente ha caracterizado su trabajo artístico, cruzando intereses sobre migraciones, sexualidades, cuerpo, y fronteras. Se trata de una búsqueda siempre alerta lejos de los parámetros y de la teoría de la producción.

Sobre la temática LGBTI+ nos comenta: "Es casi imposible que no me salga" (comunicación personal 21 de junio 2018); menciona las nuevas generaciones como una de sus inspiraciones y su intencionalidad de incidir. Ha participado también en colaboraciones con otros grupos de arte que se han dedicado a escribir poesía como el caso de Voces Fieras Video-Poética en coordinación con Contracultura de Nicaragua, un grupo de mujeres escritoras de poesía centroamericana.

Definitivamente se conecta más con esos espacios de sororidad, feminista y de activismo queer, sobre lo cual nos comparte lo siguiente: "me libero más yo, me trabajo más yo como persona compartiendo desde la identidad del ser, desde mis sentimientos, mis fuerzas, mis composiciones y mis identidades" (comunicación personal 21 de junio 2018). En estos espacios o colectivos de arte en los que ha participado, lugar desde el cual desarrolla sus creaciones artísticas, se concibe el término "manada" como ese elemento identitario relevante que les hace sentirse acuerpadas. Son colectivos que no necesariamente son conciliables con el teatro o no siempre coinciden; implica un reconocimiento de su identidad. Poder definirse desde su identidad diversa le permite existir en ese espacio como "persona queer": "si existo como persona no binaria es porque puedo hablar, porque quiero hablar, porque ten- 
go cosas que decir y existo alrededor de personas que están exactamente en lo mismo; es muy diferente a tener que hacer toda la explicación del mundo" (comunicación personal 21 de junio 2018). En los vínculos a pie de página se incluyen los vínculos del blog artístico de la artista.

\section{Teatro y videopoética}

Entrando brevemente al análisis de dos de sus obras, comienzo con Kixim (Azofeifa 2017), una propuesta que inicia con imágenes de chicas y chicos bailando libres, que intentan romper con estereotipos, escena que se ve interrumpida con la presencia de una mirada masculina e impositiva que invade el espacio corporal. Hace una diferenciación entre lo que puede significar la búsqueda identitaria entre un chico y una chica, y refleja constantemente la masculinidad normada mediante movimientos. Siempre dentro de esa posible búsqueda, aparece y reaparece la mirada externa, esa que aniquila la experimentación de un posible deseo y más bien se impone como un dictamen social.

Sus propuestas abordan distintas manifestaciones de violencia que finalmente se entrecruzan, tal como lo expone la teoría feminista de la interseccionalidad: "se convierten en una forma de externar las múltiples violencias (la estructural, al final de cuentas) y de aceptar y visibilizar las múltiples migraciones que sufro (y pluralizo) por medio del arte, la sexualidad, el género y los desplazamientos físicos de tantas personas migrantes" (comunicación personal 21 de junio 2018 ).

Mientras que en otra de sus obras llamada Mi apellido (Azofeifa 2018), la artista resuelve una búsqueda más personal e íntima que tiene sus raíces en la relación paternal, el cuestionamiento del patriarcado, la violencia, la heteronormatividad y los regímenes sobre la identidad a partir del apellido paterno. Incluso en su cotidianidad, el uso del apellido paterno aparece, se borra, reaparece, olvida, quiere olvidar, vuelve y retoma cuestionando la norma de la irrenunciabilidad eterna del apellido y del vínculo paterno (no querido, no deseado o incluso atravesado por la violencia).

Laura Contreras. Actriz, performer y poeta. Lugar y año de nacimiento: San José. 1982

Desde muy niña, a la edad de 7 u 8 años soñaba con estudiar actuación; sin embargo, como consecuencia de un accidente que le ocasionó graves quemaduras, no pudo ingresar al Colegio Castella. Su madre y su padre hacen un gran esfuerzo para matricularla en una escuela privada y al mismo tiempo comienza a recibir talleres sobre arte y escritura en la biblioteca Carmen Lyra. Aunque se formó como asistente dental, se involucra con el arte gracias a la escritura, a sus 18 años su madre y su padre le obsequian la publicación de su primer libro: La mujer hábil a la luna, una recopilación de escritos infan- 
tiles. A partir de este libro conoce el grupo Café Cultural Francisco Zúñiga en San Carlos, lugar donde vivió algunos años; allí inicia talleres sobre la escritura de textos. Nos dice que tuvo algunos años de "sequía" que le atribuye a su experiencia como madre. Retoma su vida y su escritura por un taller que imparten las Colectivas Irreversibles, con su primer taller sobre spoken word: "me enamoré locamente de lo que es el spoken word, la poesía escénica y la oralidad poética" (comunicación personal 2 de julio 2018).

Laura ha participado de otras expresiones de arte, como, por ejemplo, el clo$w n$, que vincula con su experiencia de vida. Obligada a pasar largos periodos en un hospital hace que despierte su interés por los(as) médicos(as) que disfrazados(as) de payasos circulaban por los hospitales infantiles; nos comenta: "curiosamente, uno de los doctores que más me hacía gracia o me hacía sentir más como en casa, era 'el doctor vacilón' porque me hacía reír" ( comunicación personal 2 de julio 2018). En el 2016, inicia cursos de teatro-clown y expresión. Actualmente, incorpora y fusiona los ejercicios de clown con el spoken word: "hago algunos ejercicios de clown; nadie sabe que son de clown pero los paso a la escritura; es decir, a la presencia escénica, a la imposición de la voz" (comunicación personal 2 de julio 2018)

Forma parte del colectivo Poesía Irreverente, donde surge Voces Fieras en el 2014. Detalla que el spoken word es relativamente nuevo en el país. Shepsa Nzinga, artista reconocida como la pionera, lo introduce por primera vez en Costa Rica. De este proceso creativo, nos cuenta sobre la obra "Tú sabes", en la que se explora la violencia sobre los cuerpos de las mujeres y las personas trans, obra en la que también participó un chico trans. Para Laura, las temáticas sobre el cuerpo y desde este siempre han sido centrales, por su experiencia de vida y la violencia sentida en el cuerpo; nos ilustra: "me toca hacer un texto sobre un agresor; llorando, me preguntaba de dónde nacen estos textos sobre violencia, algo que siempre he rechazado. Quizá mi experiencia no fue sobre violencia sexual, pero sí sobre la violencia corporal que viví en hospitales" (comunicación personal 2 de julio 2018).

Esta experiencia de escritura le hace repensar sobre la agencia de su propio cuerpo; sus largos periodos de estadía en hospitales le hacen reflexionar sobre el significado del dolor físico y sobre la expropiación de nuestros saberes negados por el poder de la medicina.

Cuando te pasan cosas en los hospitales o cuando naces con una malformación, siempre que hay dolor, te dicen: “¡Es por su bien!”; mi cuerpo y mi mente tenía guardada esa frase: “¡Es por tu bien!” Duré meses en un hospital con dolor; hasta los 21 años decidí no operarme jamás (comunicación personal 2 de julio 2018).

Con esta anécdota, la artista reflexiona sobre la capacidad del arte, "la psicología del arte" como ella lo define, para desbloquear las vivencias e historias 
corporales. "Esa organicidad que no sabía que existía" y que de manera casi involuntaria surge como experiencias encarnadas. Laura define su paso por el arte como un acto de sobrevivencia: "a mí me salvó la poesía que me encontró y me salvó el feminismo, que me ha dado herramientas para poder crecer y poder trabajarme" (comunicación personal 2 de julio 2018). En los vínculos a pie de página se puede apreciar parte de la obra de Laura (Contreras 2017, Contreras y Mora 2019).

\section{El poema: "Hoy me negaron mi existencia 3 veces"}

El poema "Hoy me negaron mi existencia 3 veces" (Contreras 2016) es un texto que refleja el trabajo crítico y la propuesta artística de Laura, recordando que la poesía es tan solo una de sus expresiones artísticas, a continuación un extracto:

Hoy negaron mi existencia 3 veces, después de eso me besaron en la mejilla, y me cambiaron por un par de versos.

Fue como sentir navajas, sobre la piel, pelar la epidermis hasta llegar al alma.

El texto inicia con la frase "hoy me negaron mi existencia 3 veces, después de eso me besaron en la mejilla", haciendo alusión al pasaje bíblico de la santa cena, en el que el personaje de Jesús prevé una relación de traición con uno de sus apóstoles. Es interesante cómo Laura recurre a este episodio para relatar una traición que le transmite un profundo dolor hasta "pelar la epidermis", como ella misma lo describe. A lo largo de su obra, se refiere a la invisibilización y cómo llegamos a convertirnos tan solo en una cifra más: "de esas cifras que no se vuelven a nombrar" hasta ser completamente invisible. Cuando solo eres una mujer más que ha sido violentada, una persona "sexualmente diversa" que simplemente se suma a las listas de opresión. Recurre también al concepto del closet y lo hace de una manera muy sensitiva; representa lo que puede significar para una persona "estar en un closet", sin poder salir a la luz, sin poder expresar abiertamente su identidad; lo describe como un closet húmedo, oscuro y lúgubre.

\section{Minor Sánchez. Bailarín y profesor de vouguing. Lugar y año de nacimiento: San José. 1988}

Es importante mencionar que Minor Sánchez es considerado uno de los pioneros en la Cultura Ballroom de nuestro país, por esa razón, parte de la infor- 
mación que nos ofreció durante la entrevista se relaciona con el surgimiento de esta cultura. Describe los detalles de la formación de las casas, llamadas houses, y una breve contextualización internacional. Actualmente, está vinculado con esta expresión artística que a su vez se relaciona con el baile vouguing; su parte más artística" la combina con su actual profesión como office manager en una empresa del sector de los call centers.

Gracias al baile Minor se relaciona con el arte. Nos expresa que a los 12 años empieza a seguir las coreografías de videos musicales de los años 90 y de la década del 2000. Formalmente, a los 16 años decide ingresar a una academia de hip hop; sin embargo, nos confiesa que nunca se identificó del todo con este baile urbano. A partir de ese momento, decide explorar otros estilos y entrenarse como bailarín y coreógrafo de manera empírica. Se conecta más con el baile llamado jazz funk, que en aquel momento, por el 2007, según nos dice, era desconocido. Ese mismo año, a sus 17 años, participa y gana una audición en un bar reconocido llamado Club Oh, que le permitió desempeñarse como bailarín de planta. Entonces, comienza a impartir clases al estilo jazz funk en una academia de baile. Forma el grupo de baile llamado Dance Pop Fussion Art, a partir del cual continúa con la formación de nuevos(as) bailarines y bailarinas. Para ese momento combina su trabajo como bailarín en Club Oh y se da a conocer después de participar en grandes eventos como bailarín y coreógrafo.

Su experiencia como bailarín en el "ambiente" o en la "vida nocturna gay" por más de 10 años le permite acercarse a las y los artistas transformistas o al arte transformista. "Empecé a darme cuenta del poco respeto que la gente le tenía a este arte y siempre traté que mi trabajo como coreógrafo se desarrollara con respeto y profesionalismo para darle una importancia grande a esta cultura nocturna" (comunicación personal 12 abril 2019).

Uno de sus alumnos lo introduce en el vogue femme: "cuando él 'vogueaba" me parecía muy interesante la forma tan particular de sus movimientos femeninos; me parecían únicos". Así inicia su interés por investigar sobre el vouguing. Afirma que encuentra videos virales sobre este baile, sobre todo en Europa, se siente cautivado por la música y los movimientos, y descubre que es parte de una cultura más grande llamada ballroom. Inicia entrenamientos $\mathrm{y}$, al mismo tiempo, incorpora pasos de este estilo de baile a sus coreografías y shows y así empieza a divulgarlo por el país. Para comprender un poco más sobre la cultura de baile urbano en Costa Rica, Minor nos introduce varios estilos o conceptos como, por ejemplo, las batallas de baile llamadas all styles; así como su nombre lo indica, en estas batallas urbanas podían participar todas las categorías de baile urbano, como una forma de impulsar otros nuevos estilos. En los primeros eventos, cuando se presenta la categoría vogue, Minor aprovecha para competir; poco a poco se va expandiendo más el estilo hasta que en compañía de amigos deciden realizar el primer ball oficial de Costa Rica con una voguer internacional llamada Dolores Ninja. Así, en el 2017, se lanza el Kiki Rainbow Ball, según Minor, el momento que marcó el inicio de la cultura ballroom en Costa Rica. 
Inspirada en los drags queens, la cultura ballroom inicia en los años 60 en New York, Estados Unidos, a pesar de que durante aquella década el concepto drag se limitaba a la práctica del travestismo y tal vez no tenía el significado político que hoy conocemos. Con la explicación más detallada de Minor, entendemos el significado del ballroom. Para las personas latinas y afroamericanas representó una expresión política, una re-apropiación de esta expresión de arte, no solo para auto-representarse artísticamente, sino también para constituirse como una comunidad familiar.

Esta necesidad de generar nuevos espacios responde al clasismo y la exclusión que existía entre gente no binaria. En los eventos organizados por la comunidad LGBTI+, quienes originalmente iniciaron esta expresión (probablemente, fueron personas estadounidenses) los drags afroamericanos y latinos no se sienten incluidos y se separan de la escena, recreando así su propia escena ballroom: "decidieron crear un movimiento underground, una propuesta más inclusiva; llegaron a ser espacios donde las personas de la comunidad LGBTI+ tuvieran la oportunidad de caminar (competir) en distintas categorías, donde los jueces juzgaban sus distintas habilidades como apariencia y actitud, y pudieran competir" (comunicación personal 12 abril 2019). Los eventos de ballroom se transforman en "momentos de fantasía" frente a un mundo lejano, en el que la fama, la fortuna y el éxito no estaban al alcance de todos y todas; eran espacios que simbolizaban esa fantasía del estrellato y la farándula. Como ya se mencionó, esta cultura además de representar una fantasía artística, se convirtió también en la creación de espacios físicos reales llamados casas o houses que se constituyen en familias con sus "mothers" y "fathers". Eran líderes con trayectoria no solo en la escena artística, sino muy respetadas que adoptaron la identidad de padres y madres y ponían a disposición sus viviendas recibiendo a otros y otras que eran expulsadas de sus familias por su expresión sexual: "Cuando las familias descubrían que sus hijos eran gais eran rechazados y expulsados de sus hogares dejándolos desheredados totalmente. Madres y padres de casas o houses adoptaban estos jóvenes y cuidaban de ellos como si fueran sus padres biológicos" (comunicación personal 12 abril 2019).

\section{La cultura ballroom y el aporte a la comunidad}

Esta cultura ha recibido una gran aceptación en Costa Rica; así lo reflejan la cantidad de "casas" o houses que existen. Minor nos explica que este crecimiento responde a los eventos, las sesiones y actividades que la comunidad realiza constantemente. Adicionalmente, nos comenta que también el interés artístico ha fomentado un mayor gusto por el entrenamiento en las distintas categorías de bailes coreográficos y pasarelas. Ha crecido muchísimo la convocatoria de los colectivos y grupos LGBTI+ que se reúnen a partir de estos eventos y por el significado que tienen las houses como lugares de congregación y cohesión. Cada house, además de tener un estilo propio de baile, desarrolla sus ideales, "su propia esencia", según palabras de Minor. Cada quien elige lahouse con la que más se identifica, dependiendo del estilo de baile y de los ideales (Sánchez 2019a) 
Adrián Figueroa. Bailarín y coreógrafo de danza contemporánea. Lugar y año de nacimiento: Osa, Puntarenas. 1979

Adrián inicia el recuento de su historia como artista compartiendo episodios de su niñez, la cual transcurre en Palmar Norte, zona sur del país. Sobre su lugar de nacimiento, nos relata que no existían espacios para acercarse al arte, excepto los que pudo conocer en la escuela como actos cívicos, presentaciones artísticas de danza, teatro, recitales, clases de artes plásticas y música, que aprovechó gracias a profesores(as) que trataron siempre de inculcar el arte. Desde sus años escolares, identifica su gusto por el arte, más que todo por las artes escénicas; nos cuenta: "siempre salía bailando típico en alguna comparsa del colegio; eso era lo que me gustaba, aún no tenía ese conocimiento de poder vivir del arte o profesionalizarse ni me pasaba por la mente; no fue hasta que me vine a San José, terminando el 'cole' a los 17 años" (comunicación personal 8 de julio 2019).

Pero la escuela no fue el único espacio ligado al arte que Adrián recuerda. nos cuenta también como un hecho relevante la relación con su abuela; crecer en compañía de su abuela representó otra forma de acercarse al arte, por ejemplo, recuerda la costumbre de ver juntos(as) el programa Atisbos, que se convierte en un referente profesional; recordemos que se trataba de un programa sobre crítica de arte, en el que se discutían temas relacionados con danza, teatro y música. De todos los programas recuerda uno en especial:

Yo siempre cuento esta historia porque es muy linda y romántica. Con 8 años, mi abuela y yo vimos una representación de danza, con mujeres vestidas de negro, brujas que pegaban brincos, la música era hipnótica, me asustaba me daba miedo, pero seguía viendo por un huequito porque me llamaba mucho la atención (comunicación personal 8 de julio 2019).

Se trataba del montaje del Bolero de Ravel, que vino a descubrir ya ingresando en la Universidad Nacional (UNA), donde estudia planificación económica y social y donde empieza a tener más relación con la danza y el teatro. En San José tiene la oportunidad de visitar los teatros y empieza a conocer personas del gremio artístico. Poco a poco, se inscribe en cursos de ballet en el Taller Nacional de Danza y en el Margarita Esquivel de forma paralela a su carrera de planificación. Una anécdota que nos relata con mucha emoción fue una visita al Teatro Nacional para la celebración de un aniversario en el 2002:

Vi que era danza y entrada gratuita ¡Fue la cosa más loca! Empieza a sonar aquella música de cuando yo tenía 
8 años; en ese momento me di cuenta de que era el Bolero de Ravel y empiezan a salir las brujas de negro; resulta que lo que Guido Sáenz en Atisbos estaba presentando era La Casa de Bernarda de Alba de Cristina Gigirey. Me quedé pegado a la silla, me ericé y en ese momento lo dije:. “¡Esto es lo que yo quiero ser!” Quiero bailar y además quiero bailar algún día para esa señora. Fue un momento como mágico y totalmente esclarecedor. (comunicación personal 8 de julio 2019).

A partir de ese momento, empieza a investigar sobre programas más sólidos de entrenamiento en danza y entrena en una academia llamada Atellier, donde solicitaban hombres para bailar. Fue una decisión difícil considerando lo que él mismo nos comenta como un inicio tardío en el baile: "estoy comenzando tarde en edad y en cuerpo; entonces, lo que vaya a hacer tenía que hacerlo intensivamente" (comunicación personal 8 de julio 2019).

Adrián nos comparte su sensación de "un cuerpo tardío" o, dicho de otra forma, una "entrada tardía" a la danza, lo que nos hace reflexionar sobre los formatos corporales o las "corporalidades normadas" para algunas prácticas, más aún en el caso de la danza. Si bien es cierto no puede ser igual (no tanto por la calidad sino por la capacidad de movimiento) un artista de más edad versus uno(a) más joven, ¿Acaso no existen otras cualidades en un artista menos joven, (sin ser de una edad muy avanzada) que pueda ofrecer otros elementos como la expresión y la fuerza escénica? Incluso la disciplina puede ser un aspecto (como en el caso de Adrián) que haga la diferencia con respecto a otros(as) artistas más jóvenes. La expresión y la fuerza escénica no se vinculan directamente con el factor edad; por lo tanto, desde estos elementos, "nunca se es un cuerpo tardío"

Así inicia su participación en el Festival Nacional de Danza y en Jóvenes Coreógrafos, entre otros; nos detalla que la primera vez que bailó danza contemporánea fue con un colectivo de amigos dirigido por Leo Serrani para una temporada llamada Desterrados danza. Posteriormente, se gradúa de bachillerato con la única intención de estudiar danza y dedicarse a bailar. Como un hecho relevante, nos dice haber conocido a la bailarina María Laura Barrantes, quien le informa de un espectáculo que solicitaba bailarines hombres. ¡Cuál fue su sorpresa! Se trataba de la academia de Cristina Gigirei.

De manera paralela, forma parte de la agrupación Danza Graffiti, dirigida por Christopher Núñez, la que considera una de las agrupaciones más hermosas en las que participó; allí baila en la coreografía Los Tiernos Anónimos: "una coreografía muy linda, con sombrillas grandes; éramos cuatro en escena, dos hombres y dos chicas; era como una propuesta más de choque, más de denuncias" (comunicación personal 8 de julio 2019). Este trabajo coreográfico 
representa su primer trabajo político o, como el mismo lo describe, un trabajo más relacionado con política: "se trató de un sentimiento de apoyo; ese sentimiento que solo nosotros entendemos; lo bonito de la agrupación es que todos nos sentíamos 'danza Graffiti'” (comunicación personal 8 de julio 2019).

Para el 2008, ya era productor de la Compañía Nacional de Danza, tiempo que representa un momento clave en su desarrollo como artista; realiza la audición y forma parte de la Compañía de El Salvador. Aunque vive por un año en El Salvador, no se desvincula y continúa dando seguimiento a proyectos en Costa Rica, como, por ejemplo, en la producción Danza Graffiti participa en Mirando al Sur que se coordina entre Costa Rica y El Salvador, con el respaldo del Centro Cultural de España.

Fue riquísimo; trataba sobre migraciones; dos meses de gira con la compañía de danza en El Salvador; experimenté lo que no había experimentado, me empoderó mucho como intérprete; en ese momento para un artista costarricense era tan importante salir del país. Volví con otra cara, una cara renovada un ¡Adrián bailarín importante, experimentado y viajado! (comunicación personal 8 de julio 2019).

A pesar de su trayectoria y participación fuera del país, para Adrián no fue fácil ingresar como bailarín a la Compañía Nacional de Danza. Nos comenta que no fue hasta el 2012, después de varios intentos y muchas audiciones: "no fue hasta el 2010 o 2011, con 30 años que entré; mi paso por la danza ha sido bastante persistente" (comunicación personal 8 de julio 2019).

Siendo integrante del elenco presentó espectáculos relevantes como Cuerpos Translúcidos, obra que trata sobre la humanidad, con la que ganó el Premio Nacional en el 2013. También fue persistente en su idea de formar parte de la Compañía Danza U de la UCR, a cargo de Luis Piedra. Al enterarse de la convocatoria de bailarines hombres para el espectáculo del Bolero de Ravel, lo convocan para integrar el elenco como invitado especial para la graduación de Danza Abierta con Luis Piedra: "Yo siento que soy un bailarín particular; mi corporalidad a veces es un poco restringida para lo que muchos coreógrafos quieren; pero, entonces yo trataba de forzarme para otras cosas" (comunicación personal 8 de julio 2019).

Realiza, asimismo, un trabajo de co-producción creando el espacio llamado Encuentro de solos Hecho a Mano, un espacio de solos (como su nombre lo indica) totalmente abierto a la experimentación, la puesta en escena, la investigación y la creatividad, labor que ha venido realizando hasta hoy. Adrián nos describe esta propuesta como: "un laboratorio para la gente que quería empezar a explorar la creación unipersonal, porque realmente en aquel en- 
8. Puede apreciar acá parte de la obra de Adríán: https://youtu.be/3X70X19mIW Q tonces la gente no se animaba tanto" (comunicación personal 8 de julio 2019).

Siendo parte de Danza Graffiti, recuerda el espectáculo Siete Colores en el 2010, que representa su primer trabajo vinculado con el tema de diversidad. El solo Homotextual, creado por Francisco Centeno con la colaboración e interpretación de Adrián, responde a una necesidad de ambos por poner en escena el tema de la exclusión: "En mi caso, esta es la obra más explícita y contestaría; te escupía en la cara las cosas; es una crítica, con el vocablo "homo" de hombre, junto con "textual". Quisimos expresar que existe un mismo texto para todos en la sociedad, cómo escribir el nombre de todos con la misma letra" (comunicación personal 8 de julio 2019).

El artista nos describe Homotextual (sobre lo que volveré más adelante) como una obra video-danza interdisciplinaria e interactiva con el público, que fusionó desde lo más sutil hasta lo más grotesco. Con este solo, Adrián se presentó durante cuatro años, desde el 2010 hasta el 2014, por distintos países en Sudamérica y España.

Aproximadamente, para el 2008 conoce a Ricardo Alfieri su actual pareja, artista plástico, pintor y dibujante; así surge la propuesta Gráfica Génesis, que ya existía (hace 20 años) como taller de arte experimental a cargo de Alfieri. La idea era generar algo más amplio incluyendo la parte escénica. Entre los resultados, se produce el festival Puro Cuerpo, únicamente por tres ediciones, así como el mes de la diversidad que se realiza durante los últimos tres años de Gráfica.

A inicios del 2019, remonta su entrenamiento y su nuevo trabajo en coordinación con Pepe Hevia. Su último trabajo que estrena en agosto del 2019 llamado Cuerpo Público lo describe como "una reflexión sobre como a veces priorizamos por sobre nuestro bienestar, mental corporal, emocional. Es una metáfora de cómo nuestro cuerpo nos deja de pertenecer, por estar a disposición de las necesidades de los demás (personas, cosas, trabajos, compromisos, sentimientos, familia e instituciones, etc.) (comunicación personal 8 de julio 2019. En el vínculo a pie de página se puede apreciar parte de la obra de Adrián. ${ }^{8}$

\section{Sobre la obra Homotextual}

El escenario de Homotextual (Centeno 2011) es en sí mismo un primer elemento de denuncia política, con una cantidad de pedazos de papel periódico haciendo referencia al discurso (de allí parte de su nombre, homotextual) por los textos sociales que nos inundan, "lo que se dice, o lo que se piensa sobre...", "lo que se debate sobre..."; en fin, los discursos que nos persiguen. Con ese detalle escénico lleno de simbolismo, la obra propone una serie de imágenes, movimientos, posturas y rutinas que sugieren la exclusión y discriminación hacia cuerpos diversos desde un discurso hetero-patriarcal incitado por la religiosidad y el cristianismo. Ello se refleja con la figura de un hombre que viste una falda y simula la postura de la crucifixión lo que además se pro- 
yecta de una manera hermosísima en la pantalla de fondo, que también es parte de la puesta; todo esto tan solo en la primera escena.

Partiendo de esta idea de representar el juicio y la violencia de un cuerpo "homotextual", este cuerpo diverso estará siempre "inundado" de una textualidad social que le acusa y le excluye contantemente. Esta textualidad no solo se presenta mediante la "inundación del discurso con los papeles de periódico", sino y además se exponen textos en la pantalla que permiten entre leer palabras como: odio, amor y dolor.

Siguiendo esta propuesta, se puede percibir una serie de movimientos de auto-agresión o de auto-rechazo hacia el mismo ser y una necesidad de lucha constante (en la frase coreográfica se refleja de manera recurrente con golpes, caídas y levantamientos), en combinación con momentos eróticos o de auto-afirmación de su corporalidad y genitalidad.

Esa búsqueda por la reivindicación de su identidad, esencia y corporalidad también se expone con fuerza en la obra con movimientos que expresan fuerza liberación y con imágenes imponentes frente al público y exposición de desnudos. Hay una parte de la obra mucho más confrontativa en la que el intérprete se dirige al público con unas palabras sobre su ser homosexual.

Lo de homotextual refiere también a la existencia de un mismo y único texto para todos y todas. No es la intención agotar el análisis de la obra: solo compartir estas percepciones y dejar abierta la invitación.

Susy Vargas. Artista plástica, fotógrafa, investigadora y docente en artes. Lugar y año de nacimiento: San José. 1967

Si nos dejáramos llevar por la grandiosa obra plástica de Susy Vargas, pensaríamos que su relación con el arte se dio siempre por medio de la plástica; sin embargo, y como sucede con otros y otras artistas, ha tenido sus momentos de coqueteo con otras expresiones de arte. En su caso, la música siempre le ha llamado la atención, aunque su obra gira principalmente sobre las artes plásticas lo hace fusionando diversas formas y texturas como: la pintura, el grabado en metal, el arte objeto, la fotografía y la fotografía intervenida. Es "la imaginería" entremezclada, lo que le apasiona como artista plástica, sin embargo, también se ha desarrollado como investigadora y escritora, sobre lo que volveré más adelante.

Nos expresa que siempre quiso estudiar música, pero cuando era niña la única posibilidad que existía era el Colegio Castella al que no pudo asistir por carencias económicas. Viajando un poco más atrás en la historia, su gusto por la música se vincula con su abuelo guitarrista; por él desarrolló mucha afinidad por los instrumentos musicales: "aprendí a tocar guitarra en el 'cole' y cuanto chunche suene yo lo sueno: un cuatro venezolano, zampoña, quenas, flauta y guitarra; pero jamás aprendí a leer música; todo a oído; me que- 
dó siempre como esa traba de la música; creo que por esa frustración me volqué a la plástica" (comunicación personal 17 de julio 2019).

De su abuelo cree haber heredado su pasión por el arte objeto, que descubre experimentando en medio de las creaciones plásticas y en la fotografía: "creo que mi primera experiencia plástica y mi amor por hacer las cosas viene de esos materiales toscos del taller de mi abuelo" (comunicación personal 17 de julio 2019).

La Casa del Artista representó para ella su primera gran oportunidad; nos comenta que tuvo que esperar un poco y fue hasta su pre-adolescencia, que inicia su colección plástica. Este espacio significó para Susy un encuentro no solo con la pintura y las artes plásticas; adicionalmente, un ambiente hermoso que le permite conocer también la literatura y acercarse a otros(as) artistas.

La expresión de arte que Susy nos comparte es una combinación de experiencias táctiles; basta con observar su trabajo para comprender lo profundo, distinto y único de su arte. Esos "bichos", como ella les llama, construidos con pedazos de madera, fueron sus primeras experiencias plásticas; quizá por la profundidad o significado que les daba a esas construcciones, creaba obras de teatro; escribía historias que daban cierta longevidad a cada pieza.

Susy recuerda que su pasión por la ciencia se reflejó desde niña en su gusto por el microscopio, telescopio y libros de arqueología que fueron sus primeros juguetes. Esto devela su faceta como investigadora. Si bien se expande como artista gracias a la pintura y la fotografía, en su camino se producen hermosos encuentros con otras expresiones de arte que también ha desarrollado por medio de libros y artículos. Cuando ingresa a la Casa del Artista, descubre su habilidad para el dibujo; pero cuando ingresa a estudiar bellas artes, definitivamente descubre su lenguaje artístico que no se limitó solo a la pintura: se amplió hacia la fotografía de maneras hermosamente creativas.

Su carrera universitaria en bellas artes tiene muy variados énfasis: pintura, cerámica, grabado en metal y xilografía. Casi de forma simultánea, inicia estudios en grabado de metal y fotografía, lo que se plasma de manera muy curiosa en sus obras, pues son una combinación entre todos estos lenguajes. Crece en ella un interés más por transformar/crear que por trabajar los materiales, especialmente con el metal industrial; la técnica del grabado en metal se convirtió en el elemento central de su creación: "fue muy rico, me enamoré del grabado en metal y después empecé a llevar fotografía, Junto con dos amigas más hicimos un cuarto oscuro en mi casa, decidí que iba a experimentar en grabado metal pintura Industrial con corrosión y herrumbre con químicos; estaba enloquecida con la química" (comunicación personal 17 de julio 2019).

¿Cómo alguien puede experimentar el arte gráfico a partir de la herrumbre o los desechos industriales? Su profunda mirada de artista hizo de esta combinación obras de una belleza única, una verdadera transformación. 
Ingresar a bellas artes y conocer a su maestro y artista plástico Giorgio Timms marca su encuentro con la fotografía; primero, ingresa como oyente a su clase de fotografía; nos detalla que no todos los profesores eran tan apasionados(as) como Timms: "Giorgio pasión, completamente enamorado; él fue uno de los primeros en homoerotismo en la fotografía" (comunicación personal 17 de julio 2019) Posteriormente, en 1988 conoce a Roberto Cabrera con quien trabaja como asistente de pintura por 5 años: "este señor llegó a abrirme la cabeza por completo" (comunicación personal 17 de julio 2019).

A partir de este proyecto de investigación sobre fotografías de Costa Rica "inevitablemente", como ella misma lo relata, se convierte en especialista en fotografía de Costa Rica. Por esa iniciativa y por su interés en la fotografía publica su primer libro de historia (periodo 1843 a 2002) sobre la fotografía en Costa Rica; realiza, además, una exposición en el Museo del Banco Central de Costa Rica (BCCR). Pero este no fue su único acercamiento con las publicaciones e investigaciones, a lo que siguió dedicándole mucho más tiempo, reconociendo que fue gracias al trabajo investigativo con Roberto $\mathrm{Ca}-$ brera que se enamora "también" de la investigación.

Actualmente, es profesora de cultura latinoamericana; nos comenta su pasión por la cultura y su esfuerzo por transmitirles a sus estudiantes sobre la historia de la cultura costarricense: "es mi pasión y mi locura; ahí les enseñó sobre danza, sobre teatro, sobre cine, sobre música, sobre todo" (comunicación personal 17 de julio 2019). Hoy se encuentra terminando un proyecto sobre la construcción imaginaria del costarricense, a partir de las decoraciones religiosas populares en casas; según su opinión: "la decoración vernácula religiosa de las casas es otra forma de conectar con el arte popular" (comunicación personal 17 de julio 2019).

\section{La diversidad presente en su obra plástica}

Desde que inicia su trabajo como artista se ha interesado por el tema del erotismo: en sus proyectos personales están presentes los temas de los cuerpos, la erótica y la diversidad: "desde que tengo uso de razón, hago arte erótico" (comunicación personal 17 de julio 2019). La fusión entre los temas erotismo y exvotos también ha sido recurrente en su obra. El interés por incorporar en sus obras el arte corporal se refleja en su participación en la exposición Detrás del Portón Rojo; desde que fue invitada como curadora para esta exposición, tenía claridad en la necesidad de incorporar el tema erótico indígena, sobre lo que Susy sigue investigando con en el apoyo de colegas de arqueología. Agrega: "yo voy a escribir desde mi visión de artista sobre el tema erótico indígena; pero empiezo a investigar y me vuelvo loca con el tema de la intervención corporal; ahora tengo un proyecto aparte sobre pigmentos corporales, simbología; el cuerpo como espacio" (comunicación personal 17 de julio 2019).

La artista nos muestra la vinculación entre la visión de corporalidad, pecado y prohibición desde el enfoque religioso y estético; esta es una dualidad presente en muchas de sus exposiciones. Lo representa mediante cuerpos eróti- 
cos, el placer y el deseo, en contraposición con la idea de cuerpo impuro o cuerpo santificado: "el cuerpo para mí es un objeto exponible, sagrado y de desear", lo que posiblemente sea opuesto al concepto de corporalidad religiosa, que siempre ha entendido el cuerpo como pecado y suciedad, dualidad que re-aparece una y otra vez en muchas de sus exposiciones (Vargas 2014).

\section{Reflexiones finales}

En proyectos anteriores inicia mi interés por estudiar las artes escénicas como parte de la línea investigativa: Feminismos, arte y corporalidades; en esta oportunidad, se trata de otros encuentros, de otros espacios; me interesa difundir un grupo de artistas cuya propuesta se sale de la formalidad de los teatros y de los museos, sin saber exactamente cuál ha sido el camino que les ha llevado a las artes. En esta diversidad de expresiones, valga la redundancia, las "muestras diversas" han encontrado su lugar. Son artistas que rebuscan nuevas fusiones y nuevas maneras de crear, en un mundo en el que no necesariamente han sido siempre invitades y bienvenides.

El artista performer e investigador colombiano Yecid Calderón propone el término "anartista" para referirse a: "aquellas personas conscientes o no de su poder creativo que se lanzan al mundo para entrometerse, habitarlo, ejecutarlo, generando realidad y pervirtiendo las órdenes de las élites modernas y capitalistas del arte de autor" (Calderón 2016,129). Ellos y ellas no siempre reconocen los espacios artísticos o académicos como las únicas opciones de estudio, creación o acercamiento a las artes; todos y todas perciben el poder creativo como poder transformador y generan sus propios espacios a partir de sus realidades; cada uno de esos artistas:

Toma consciencia de su raza, de su clase, de su sexualidad, antes que nada y por ello se comprometen con la transformación de las circunstancias de humillación y maltrato de sí mismo y de otros que opera a través de esos marcadores de exclusión, aquí y ahora (Calderón 2016, 130).

Me corresponde, entonces, visibilizar el trabajo de los, las y les "anartistas" que forman parte de este archivo diverso, no siempre conscientes del poder de sus expresiones, pero presentes con sus propuestas disidentes.

\section{Diversidad, variedad e invisibilización}


Siendo un archivo en construcción, ya es posible reconocer la amplitud de formas y de expresiones, que aunque no es el objetivo describirlas según sus definiciones o categorías puramente técnicas, sí es interesante subrayar la gran variedad, lo que de nuevo me hace cuestionar la poca visibilización de un arte tan rico y diversamente extenso, en cantidad y en calidad.

Encuentro una búsqueda reflexiva común, la mayoría de los y las artistas reconocen la teoría de género como su posicionamiento teórico-político, o como una guía (no necesariamente teórica). Además, se interesan por el enfoque de derechos humanos con una intención clara de incorporar en sus obras la reflexión política en torno a la diversidad.

Como he venido profundizando a lo largo de mi investigación, el concepto de diversidad lo planteo desde la amplitud de su significado que abarca además de diversidad sexual, una diversidad de expresiones y formas de vivir el arte, lo que permite a la vez, recordar cómo las categorías de arte se superponen de maneras cada vez más invisibles. La intención no es descomponer las categorías formales, porque sí hay: siempre han existido y algunas de ellas, no todas, mantienen sus especificidades; aunque también han mutado tanto que le permite a cada artista agenciar su propia expresión.

Lo anterior propone otra reflexión, no solo sobre el concepto de arte o sobre lo que entendemos por arte; también sobre quien es artista y quién no. Con los y las artistas presentes en este archivo, se evidencia que las expresiones de arte siguen vivas y cambiantes. Yecid Calderón lo define de la siguiente manera:

Si hay un uso o utilidad en el arte, en caso de que a eso se le puede llamar uso o utilidad -creo que más bien es función, en el sentido griego de ergón; o sea, como una especie de actividad muy activa por decirlo de alguna manera, una actividad que aún no está dispuesta o regida bajo una forma específica (Calderón 2016, 102).

\section{Recuperación de la experiencia}

Como ya lo he señalado, la elaboración de este archivo se inserta dentro del principio feminista de la recuperación de la experiencia, lo que Mohanty señala como la "experiencia compartida", que es donde radica la riqueza. Es cierto que cada artista y cada expresión de arte tienen un valor único por sí sola; pero es en la construcción de un archivo cuando se refleja la grandeza del registro. Parafraseando a Mohanty, un solo relato es fuerte; pero cuando son muchos, es aún más poderoso, lo que no debería pasar inadvertido.

Es innegable dimensionar el crecimiento acelerado de un arte diverso y disidente y, al mismo tiempo, la falta de espacios formales, razón por la cual ellos, ellas y elles utilizan todos los espacios posibles para visibilizarse. 
¿Cómo podemos interpretar un archivo? La lectura de una obra puede ser reinterpretada de distintas maneras, según sea la postura de quien lea: "las lecturas no surgen naturalmente del texto, sino que son producidas; están situadas sobre campos de significación y de poder" (Haraway 1987 en Bach 2010, 95). El posicionamiento político que oriente y apunte la construcción de un archivo repercute en la interpretación que deeste se realice; por ello, es relevante extraer esa lectura corporal, esos lenguajes que el artista o la artista comparten gracias a su relato; es una tarea de traducción artística. Por ejemplo, el lenguaje de la danza se va adquiriendo con la práctica; es un sentir distinto y propio que facilita la interpretación. La investigadora y bailarina Laura Citro ha estudiado el movimiento y lo describe como una "acción corporizada":

No se trata tanto de efectuar una recopilación exhaustiva de datos cronológicos sobre un campo de estudio, sino más bien de exponer una nueva manera de reflexionar sobre algunos episodios de una historia disciplinar que concibo y siento como inevitablemente encarnada: escrita con los cuerpos, aunque a veces estos hayan intentado ser borrados (Citro 2011, 10).

Son relatos en los cuales existe una presencia corporal porque el cuerpo se convierte en un recurso de investigación y generación de conocimiento y no un objeto inactivo. Autoras como Alcoff (recuperada también del análisis de Bach) comparten importantes reflexiones al respecto, más explícitamente sobre la "experiencia encarnada" a partir de las mujeres sobrevivientes de incesto. Es interesante cómo esta autora señala que no puede haber otra forma de transmitir un relato tan terrible como puede ser una violación, sino es a partir de los relatos "encarnados"; es decir, sentidos y vividos en el cuerpo. (Alcoff en Bach 2010, 115).

Recurro de nuevo a Bach, que he mencionado a lo largo del artículo para cerrar esta idea sobre la importancia de colocar en la experiencia personal y en los relatos "ordinarios" una posibilidad para construir principios teóricos. La relevancia de un registro está en la suma de los relatos; precisamente, la experiencia de vida mediante esos relatos que comparten una realidad similar es un sentido de exclusión e invisibilización común, lo que fortalece y colectiviza el archivo.

Los y las artistas presentes en este archivo tienen mucho en común: comparten sus realidades, crecieron en un contexto poco favorable para su quehacer artístico, con limitadas posibilidades económicas para el desarrollo de su práctica. A pesar de haber crecido en situaciones y lugares que no fueron los más convenientes, coinciden en haber tenido esos espacios mínimos donde compartir el arte, familiares que de una u otra forma se relacionaron con expresión artísticas y que fueron claves para su crecimiento como artistas. La 
necesidad por expresar su inconformidad con ciertas normas sociales les ha acercado. La necesidad de confrontar la heteronormatividad, luchar contra mitos y mandatos establecidos por la construcción binaria y lo género-estructurados se manifiesta en sus obras.

Las y los artistas que agrego al archivo participan en la escena diversa de nuestro país por medio de variadas expresiones de arte, con el spoken word, la poesía y el performance de Angélica Azofeifa y Laura Contreras, (además de la dirección y actuación en el caso de Angélica, y del teatro-clown en el caso de Laura). Desde el movimiento, ya sea danza moderna y ballroom participan Adrián Figueroa y Minor Sánchez; y, por último, en las artes plásticas y la fotografía se incluye el relato de Susy Vargas.

Han intervenido la escena, la calle, la escritura y la plástica desde lugares distintos. Minor introduce al país (en compañía de otros artistas) la cultura del ballroom; su aporte ha sido replicar y sostener esta propuesta mediante eventos, clases y la formación de casas o houses, y que constituye un espacio que convoca muchísimas personas LGTBI+.

Por su parte, Adrián, además de haber aportado como gestor, bailarín y coreógrafo, incorpora la diversidad desde hace más de diez años con un lenguaje claramente disidente; son trabajos coreográficos que representan para él un "despertar político".

Susy, en una obra inmensa en tiempo y experimentación, se atreve a fusionar cuerpo, dualidad y erotismo; el recorrido por su propuesta estética es interminable. Son relatos de un cuerpo que cuenta un dolor físico y reafirma su autonomía en medio incluso de decisiones médicas como lo comparte Laura. Los escritos y esfuerzos escénicos de Angélica se inspiran en la diversidad sexual y desde la lucha decolonial.

La resignificación de las corporalidades se hace presente con mucha fuerza en estos cinco artistas, ese "volver al cuerpo", centrarse en el cuerpo: en un cuerpo diverso, un cuerpo tardío para una técnica o para la norma, un cuerpo alterado, un cuerpo que incomoda o un cuerpo excluido. La diversidad está inevitablemente presente en sus obras porque se halla en sus cuerpos, así como en todos los cuerpos humanos.

\section{Referencias}

Azofeifa Angélica. 2017. Kixím. Guion de creación colectiva. 25 de julio del 2019. https://vimeo.com/258779818

Azofeifa Angélica. 2018. Mi apellido. 25 de Julio del 2019. Videopoética. Costa Rica/Nicaragua

Azofeifa, Angélica. 2018 <https://angazofeifa.wordpress.com/spoken-word/ 
Bach, Ana María. 2010. Las voces de la experiencia. El viraje de la filosofía feminista. Buenos Aires: Editorial Biblos.

Bailey, Marlon. 2014. Engendering space: Ballroom culture and the spatial practice of possibility in Detroit. Reino Unido: Gender, Place \& Culture. 21(4), 489-507.

Calderón, Yecid 2016. Deviniendo loca. Textualidades de una marica sureada. Chile: Los libros de la mujer rota.

Centeno, Francisco. 2011. Homotextual. [Danza]. Gráfica Génesis. San José. 2011. Danza Contemporánea.

Citro, Laura. 2011. Cuando escribimos un bailamos. Antropología de y desde las danzas Buenos Aires: Editorial Biblos..

Contreras, Laura y Mora Diego. 2019 Sin título. 15 de enero del 2019 https://youtu.be/LPVcc6ilh4s.

Contreras, Laura. 2016. Hoy me negaron mi existencia 3 veces. Verso Diverso. Antología Poética. LGBTIQ. San José. Cartón-Era.

Contreras,

Laura.

2017

https://www.google.com/amp/s/400elefantes.wordpress.com/2017/11/06 /laura-contreras-no-quiero-una-sociedad-que-encienda-velas/amp/ > [Acceso 15 de enero del 2019]

Contreras, Laura. 2017. Atarte. 15 de enero del 2019. https://youtu.be/pNZUHy-sSlc

Contreras, Laura. 2018. Miles de veces muerta por un patriarcado que ensangra las vidas de todas. 15 de enero del 2019. http://www.vocesnuestras.org/2018-11-16/poesia-miles-veces-muertapatriarcado-ensangra-vidas-todas. Poesía

Cultura UNAM. https://cultura.unam.mx/evento/elements-of-vogue-un-casode-estudio-de-performance-radical-inauguracion [Acceso el 25 de abril del 2019]

Figueroa, Adrián. 2011. Homotextual. 15 de agosto del 2018. https://youtu.be/3X70X19mIWQ .

López, Paz 2019. Carmen Beuchat. ¿Qué puede un cuerpo? http://artishockrevista.com/2019/05/15/carmen-beuchat-que-puede-uncuerpo/ [Acceso 15 Agosto del 2019]

Marchante Hueso, Ana. 2015 «Transbutch. Luchas fronterizas de género entre el arte y la política». Tesis. Programa de Doctorado.doctoral. Facultad de Bellas Artes. Universidad de Barcelona.

Missé, Miquel 2018. A la conquista del cuerpo equivocado. España. Egales.

Oliva, Patricia. 2019. Archivo Diverso Costa Rica. 1a parte. Expresiones de arte transgresor. En No solo musas. Mujeres creadoras en el arte iberoamericano. Monográfico Atrio 1, 67-78. Sevilla: Universidad Pablo de Olavide, Atrio. Sevilla 
Sánchez, $\quad$ Minor. $\quad 20 \quad$ de julio del 2019.https://www.facebook.com/kikirainbowballcr/videos/191907401171 7829/

Sánchez, Minor. 2019a. Hands performance versus arms control. The Abstract voghe nigth. Kiki Scene. 25 de agosto del 2019.https://www.youtube.com/watch?v=iXTiabdZO8Y [Acceso el 25 de agosto del 2019]

Sánchez, Minor. 2019b. Ota Runway Batteles-Grezzy: Gods era Kiki Ball. 25 de agosto del 2019

Sánchez, Minor.2019. Female Figure versus Butch Queen Performance Final. Grezzy: Gods Era Kiki Ball. 25 de agosto del 2019. https://www.youtube.com/watch?v=MDZPGBHi5DU

Taylor, Diana y Marcela Fuentes (edits.) 2011. Estudios avanzados de performance. México D,F. Introducción.

Vargas, Susy. $2014<$ http://museodelasmujeres.co.cr/2014/07/poemascotidianos-por-sussy-vargas/> [Acceso 25 de Agosto del 2019] 